\title{
Prognostic value of right ventricular ejection fraction determined by cardiac magnetic resonance
} Ijaz Ahmad*, Azizul Rehman, Joe Lau, Betty Hua, Frida Ashurova, Geetha P Bhumireddy, Faisal Ali, Charles Vu, Joshua Fogel, Sorin J Brener, Terrence Sacchi and John F Heitner

Address: New York Methodist Hospital, Brooklyn, NY, USA

* Corresponding author

from 13th Annual SCMR Scientific Sessions

Phoenix, AZ, USA. 21-24 January 2010

Published: 21 January 2010

Journal of Cardiovascular Magnetic Resonance 20 I0, I2(SuppI I):P30 I doi:I0.I I86/I532-429X-I2-SI-P30I

This abstract is available from: http://jcmr-online.com/content/I2/SI/P30I

(c) 2010 Ahmad et al; licensee BioMed Central Ltd.

\section{Introduction}

Although studies have shown that right ventricular ejection fraction (RVEF) is an independent predictor of survival in patients with myocardial infarction and moderate left heart failure, there is scant data available on the prognostic significance of RVEF in patients with preserved left ventricular ejection fraction (LVEF), partly due to challenges in imaging the right ventricle (RV) due to its amorphous geometry. Recent technological advances in cardiac magnetic resonance (CMR) have allowed the RVEF to be assessed with greater accuracy.

\section{Purpose}

To assess the prognostic ability of RVEF, independent of LVEF, for the development of cardiovascular outcomes: death, recurrent hospitalization and worsening CHF (New York Heart Association Class).

\section{Methods}

We prospectively evaluated 733 consecutive patients referred to our CMR center with the following indications: evaluation of left ventricular function $(37 \%)$, viability $(30 \%)$, valvular disease $(21 \%)$, and other $(12 \%)$. A comprehensive history and serologic markers (pro-BNP, Lipid profile, and CRP) were obtained on the day of the procedure. Persons blinded to patient data manually performed region of interest curves and the LVEF and RVEF were calculated via computer software analysis. Patients were divided into 4 groups: A) Normal RVEF and LVEF, B) Low
RVEF and normal LVEF, C) Normal RVEF and Low LVEF, D) Low RVEF and LVEF. Normal LVEF and RVEF were considered $\geq 50 \%$ and RVEF $\geq 35 \%$, respectively. Statistical analyses were performed using Kaplan Meier survival curves with the log-rank test and Cox regression analysis adjusting for the relevant covariates. Follow-up data were obtained via phone interview, medical records review when necessary, and the social security death index.

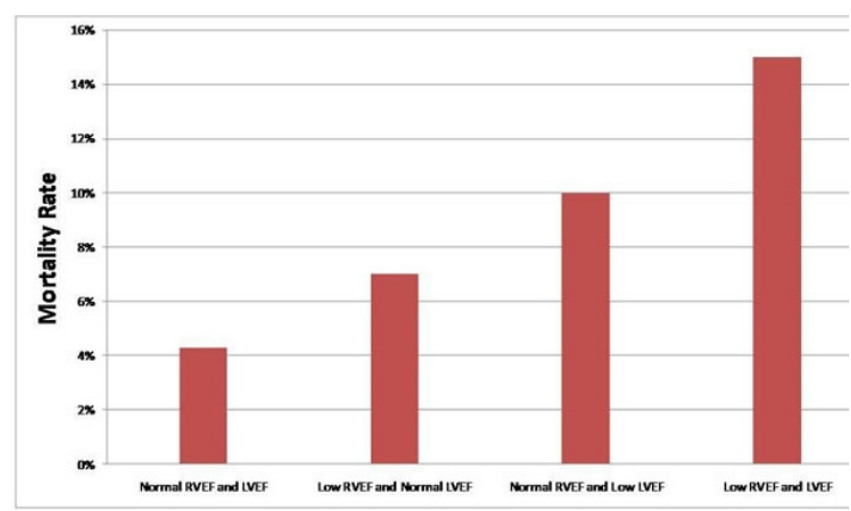

Figure I 


\section{Results}

The mean age of the patient population was $59 \pm 17$ years, 424 were males. The average LVEF was $50 \pm 3 \%$ and the average RVEF $40 \pm 5 \%$. The mean follow up was $14 \pm 2$ months. There were total of 260 outcomes observed: 62 deaths, 43 recurrent hospitalizations, 155 worsening CHF. Group A had 326 patients, 107 composite outcome, and 14 deaths. Group B had 102 patients, 39 composite outcome, and 7 deaths. Group C had 147 patients, 47 composite outcome, and 7 deaths. Group D had 158 patients, 67 composite outcome, and 24 deaths. The logrank test showed significance between the 4 groups ( $\mathrm{p}=$ 0.02). Cox regression analysis adjusting for relevant covariates showed that both LVEF and RVEF were independent predictors of the cardiovascular outcomes $(<0.01)$, Figure 1.

\section{Conclusion}

RVEF, independent of LVEF, predicts cardiovascular outcomes in a selected population of patients referred for CMR.

Publish with Biomed Central and every scientist can read your work free of charge

"BioMed Central will be the most significant development for disseminating the results of biomedical research in our lifetime." Sir Paul Nurse, Cancer Research UK

Your research papers will be:

- available free of charge to the entire biomedical community

- peer reviewed and published immediately upon acceptance

- cited in PubMed and archived on PubMed Central

- yours - you keep the copyright

Submit your manuscript here:

http://www.biomedcentral.com/info/publishing_adv.asp 